\title{
The crossroads of gastroenterology and psychiatry - what benefits can psychiatry provide for the treatment of patients suffering from gastrointestinal symptoms
}

\author{
Jerzy A. Sobański ${ }^{1}$, Katarzyna Klasa², Michał Mielimąka ${ }^{1}$, Krzysztof Rutkowski ${ }^{1}$, Edyta Dembińska ${ }^{1}$, \\ Łukasz Müldner-Nieckowski ${ }^{1}$, Katarzyna Cyranka', Bogna Smiatek-Mazgaj ${ }^{1}$, Lech Popiołek ${ }^{1}$
}

${ }^{1}$ Psychotherapy Department, Jagiellonian University Medical College, Krakow, Poland

${ }^{2}$ Psychotherapy Department, University Hospital, Krakow, Poland

Key words: somatisation, anxiety, irritable bowel syndrome, comorbidity.

Address for correspondence: Jerzy A. Sobański MD, PhD, Psychotherapy Department, Jagiellonian University Medical College, 14 Lenartowicza St, 31-138 Krakow, Poland, phone: +48 1263312 03, +48 1263372 16, e-mail: molocko@poczta.fm

\begin{abstract}
Introduction: Gastrointestinal symptoms are very common in the general population. Many of them coincide with mental disorders (especially with neuroses, stress-related disorders, somatisation disorders, autonomic dysfunction, and anxiety) that are associated with psychological trauma, conflicts, and difficulties with interpersonal relationships.

Aim: Assessment of the association between gastrointestinal complaints and stressful situations in relationships, among patients admitted to day hospital for neurotic and behavioural disorders.

Material and methods: Analysis of the likelihood of co-occurrence of abdominal symptoms and stressful situations, reported by patients before admission, in a large group of subjects treated with psychotherapy.

Results: Gastrointestinal symptoms were highly prevalent in the studied group (they were reported by $40-50 \%$ of patients). The most common complaints in women were: loss of appetite (52\%), nausea (49\%), and constipation and flatulence (45\%). In men the most prevalent symptoms were: loss of appetite (47\%), heartburn (44\%), and flatulence (43\%). Functional gastrointestinal symptoms (especially vomiting in cases of nervousness in females or heartburn in males) were significantly associated with greater likelihood of current difficulties in interpersonal relationships, such as conflicts with partner/spouse or parent.

Conclusions: The results suggest that in many cases symptoms of anxiety disorders or somatisation disorders coexisted with irritable bowel syndrome and functional dyspepsia.
\end{abstract}

\section{Introduction}

Gastrointestinal symptoms such as dyspepsia, constipation, diarrhoea, and abdominal pain are highly prevalent in the general population. They are also among the most common reasons for seeking medical care. Acute gastrointestinal disorders (for example: appendicitis or peptic ulcer perforation) are among the most serious life-threatening conditions and require immediate surgical intervention. At the same time very common gastrointestinal complaints, so-called functional symptoms, are associated with autonomic dysfunction. Nowadays they are described as a separate disorder (ICD-10 F45.3; DSM-V: Somatic symptom disorder - SSD) [1, 2]. This overlap of somatic problems - belonging to the area of gastroenterology, and mental disorders - belonging to the area of psychiatry and psychotherapy, results in many complications. On the one hand, patients seeking medical care are often not prepared for the diagnosis: "absence of organic disease" and usually turn to a number of experts in search for verification and confirmation of the diagnosis of somatic disease. On the other hand, in the case of confirmation of organic disease, psychological factors, which could have important implications for the course of the illness and the patient's involvement in treatment, are often omitted. It is generally accepted that psychological factors influence the course of 
the disease, including its severity and frequency of exacerbations [3]. Attention is paid to the analysis of mental state associated with somatic disorders, such as irritable bowel syndrome (IBS) and conditions similar to IBS [4, 5], ulcer disease, functional dyspepsia [6], and digestive disorders unrelated to erosion [e.g. 7]. A study by Walter et al. revealed that abdominal pain, even if it does not meet IBS criteria, is often connected with greater risk of the presence of anxiety and depression symptoms. It is also associated with the severity of these symptoms [8]. A striking illustration of the importance of the psychological burden associated with gastrointestinal symptoms is the observation that the majority (50-90\%) of patients who start treatment of IBS suffered from at least one mental disorder: a depressive disorder, a generalised anxiety disorder, a panic disorder, a social phobia, a somatisation disorder, or posttraumatic stress disorder (PTSD). These mental disorders clearly exacerbate their condition $[4,9]$.

Psychological factors associated with gastrointestinal disorders and discomfort include: current burdensome life events, abnormal relationships with parents, abuse [10-13], anxiety, depressiveness, neuroticism, immature defence mechanisms, inadequate social support [7, 14], and difficulties in interpersonal relationships (associated with hypersensitivity in the relationship) [15]. Some studies suggest that there is a link between abdominal symptoms and sexual experience in men who had early (at the age of 14-16 years) sexual initiation [16]. What is more, functional abdominal pain is associated with a history of sexual abuse, both in children and in adults [17].

Due to the high incidence of gastrointestinal symptoms in patients suffering from psychiatric disorders (especially neuroses), it is crucial to identify the main risk factors for "intestinal complaints" and other ailments that fall within the spectrum of symptoms of neurotic disorders (somatisation disorders, anxiety disorders, and others).

It is estimated that in the case of IBS, gastrointestinal complaints are a more important reason than the psychiatric manifestations for seeking medical care [18]. Nevertheless, there are two main factors responsible for excessive use of health care resources by patients with IBS. These include: somatisation disorder comorbidity [19] and difficulties in relationships with doctors - for example: refusing to admit that IBS has a psychological background or so-called "pseudo-healthy" behaviours, such as extra visits and medical consultations, demanding the change of drugs, absenteeism from work, use of benzodiazepines, etc. [20].

The association between IBS and psychiatric disorders is commonly recognised. That is why, in the case of IBS treatment, pharmacotherapy and psychotherapy are often combined. Obviously it should be mentioned that there are some protests against labelling people suffering from IBS as psychiatric patients [21]. Back in the 90s the belief that mental disorders are a cause of IBS was withdrawn in favour of the view that IBS and mental disorders often co-occur. It was also observed that treatment of psychogenic component reduces functional gastrointestinal symptoms [22]. Among the most important evidence of the relevance of offering psychotherapy in neurotic disorders with gastrointestinal symptoms is its high efficiency, even if IBS is accompanied by panic disorder (e.g. [23]).

The nuisance of gastric complaints associated with psychological factors increases in the process of somatosensory amplification, when the patient focuses on the alleged threat [24]. Therefore, one of the best methods to reveal the causes of gastrointestinal symptoms is the analysis of the context (e.g. interpersonal conflicts or psychological trauma) in which the symptoms occur $[12,16]$.

Paradoxically, Polish psychiatrists are not very interested in functional gastrointestinal disorders (this became clear after the analysis of the recent issues of "Psychiatria Polska", e.g. [25]). Much more attention is paid to eating disorders (e.g. [26, 27]). It is a paradox because neurotic disorders are among the most serious medical problems [28] and they are commonly misdiagnosed and not treated properly [29]. This paper is an attempt to make up for this lack.

\section{Aim}

Estimation of the prevalence of gastrointestinal complaints in patients admitted to day hospital for neurotic and behavioural disorders. Assessment of the association between gastrointestinal complaints and stressful life events, related to partnership or marriage, among these patients.

\section{Material and methods}

Data regarding stressful situations concerning partnership or marriage were gathered using a structured Life Inventory, which was filled out, prior to the therapy, by patients who were hospitalised between 1980 and 2002. Qualification for treatment was based on psychiatric assessment, psychological examination, and a battery of questionnaires, which allowed the exclusion of disorders related to schizophrenia, affective, exogenous, or pseudoneurotic disorders, and serious somatic diseases. Information about the occurrence and severity of symptoms were obtained using the KO "O" Symptom Checklist by J. Aleksandrowicz, which was filled out by patients prior to psychotherapy [12]. Answers to six of seven items of the KO "O" checklist (diarrhoea, constipation, vomiting, 
Table I. Severity of neurotic symptoms, diagnosis according to the ICD-10 and socio-demographic data of patients

\begin{tabular}{|c|c|c|}
\hline Parameter & Female $(n=2582)$ & Male $(n=1347)$ \\
\hline Global severity of symptoms, mean \pm SD (median) & $394 \pm 152(387)$ & $349 \pm 151(336)$ \\
\hline \multicolumn{3}{|l|}{ Primary diagnostic codes according to ICD-10 [\%]: } \\
\hline F44/45 Dissociative or somatoform disorders & 29 & 25 \\
\hline F60 Personality disorders & 23 & 29 \\
\hline F40/F41 Anxiety disorders & 17 & 16 \\
\hline F48 Neurasthenia & 7 & 14 \\
\hline F34 Dysthymia & 7 & 5 \\
\hline F50 Eating disorders & 5 & 0 \\
\hline F42 Obsessive-compulsive disorders & 2 & 2 \\
\hline F43 Reaction to stress and adjustment disorders & 1 & 2 \\
\hline Other & 3 & 2 \\
\hline No data & 6 & 6 \\
\hline Age, mean \pm SD (median) & $33 \pm 9(33)$ & $32 \pm 9(28)$ \\
\hline \multicolumn{3}{|l|}{ Education [\%]: } \\
\hline Preschool/Primary education & 9 & 12 \\
\hline Secondary education (including students) & 57 & 56 \\
\hline Higher education & 34 & 32 \\
\hline Employed [\%] & 59 & 70 \\
\hline Unemployed [\%]: & 41 & 30 \\
\hline Pensioners & 10 & 7 \\
\hline Students & 23 & 24 \\
\hline
\end{tabular}

nausea, heartburn, flatulence) regarding functional complaints were selected as reports of crucial functional gastrointestinal symptoms according to Rome III Diagnostic Criteria for FGIDs [30, 31]; however, data obtained from the database usually did not allow completion of the diagnosis (e.g. time criteria had not been checked precisely enough). Exclusion of non-functional gastrointestinal disorders was based on pre-therapy medical consultations (including, when necessary, gastrologist's consultation), which allowed fulfilment of the 'absence' criteria of Rome III [30, 31]. Appetite loss was added as a separate psychogenic complaint directly reported by patients. Most of the 3929 surveyed people were diagnosed with one neurotic disorder or a personality disorder as a primary diagnosis with accompanying neurotic disorder. Information about selected sociodemographic characteristics of the studied group are presented in Table I. Data obtained using routine diagnostic tests (after receiving informed consent of the patients) were anonymised. Bioethics Committee approval: UJKBET/111/B/2009 was obtained. Odds ratios (OR) for the coexistence of the two nominal variables (life context and symptom) were calculated using logistic regression [16].

\section{Statistical analysis}

Licensed StatSoft Statistica PL software was used.

\section{Results}

The results of analysis of the incidence and severity of extreme gastrointestinal symptoms, which were reported by patients using the KO "O" Symptom Checklist, are presented below.

As shown in Table II, the vast majority of the analysed symptoms were significantly more frequent in females than in males (significantly higher prevalence in males was found only in the case of heartburn). The most common complaint in both sexes was loss of appetite (in women 53\%, in men $47 \%$ ). Due to such significant differences in symptoms in males and females, and the potential diversity of experiencing stressful life events between men and women, further analyses were performed in these two subgroups separately. The results of logistic regression analysis were classified as significant when the odds ratios (OR) was higher than 1.5 and the $p$-value was lower than 0.05. Regression analysis results are listed below (statistical significance is marked as $\left.{ }^{*} p<0.05,{ }^{* *} p<0.01,{ }^{* * *} p<0.001\right)$. 
Table II. Occurrence of gastrointestinal symptoms

\begin{tabular}{|c|c|c|c|}
\hline KO "O" checklist symptom as reported by patients & $\begin{array}{l}\text { Supposed place as core symptom } \\
\text { in Rome III Criteria [30] }\end{array}$ & Female [\%] & Male $[\%]$ \\
\hline Diarrhoea & C4 & 30 & 31 \\
\hline Constipation & $\mathrm{C} 3$ & $* * * 45$ & 27 \\
\hline Vomiting when nervous & $\mathrm{B} 3 \mathrm{~b}$ & $* * * 26$ & 16 \\
\hline Appetite loss & $n / a$ & $* * * 53$ & 47 \\
\hline Nausea, feeling sick & B3a & $* * * 49$ & 39 \\
\hline "Heartburn" & $\mathrm{Al}$ and/or $\mathrm{Bl}$ & 37 & $* * * 44$ \\
\hline Flatulence, passing gas involuntarily & C2 & 45 & 43 \\
\hline
\end{tabular}

\section{The co-occurrence of diarrhoea and stressful situations in males and females}

In females who reported symptoms of chronic diarrhoea the risk of difficulties in relationships was significantly higher than in women without diarrhoea. The difficulties in relationships mentioned in the previous sentence included: a) conflict expressed by passive-aggressive silence or insults (OR ${ }^{* * *} 1.58,95 \% \mathrm{Cl}: 1.24-$ 2.01), b) the feeling that the patient's partner hates her $(\mathrm{OR} * 2.34,95 \% \mathrm{Cl}: 1.19-4.60)$, and c) the patient's conflict with the father of her partner (OR ${ }^{* *} 1.91,95 \% \mathrm{Cl}$ : 1.30-2.81). In males, diarrhoea coexisted more often with the following difficulties in the relationship: the patient's conflict with his partner's father (OR *2.00, 95\% Cl: 1.07-3.74) and a sense that the patient put much more effort into establishing the relationship than his partner did (OR *1.65, 95\% Cl: 1.16-2.33).

\section{The co-occurrence of constipation and stressful situations in males and females}

Constipation in females was not associated significantly with any aspect of the relationship. In males who suffered from constipation, the risk of the following difficulties in the relationship was significantly raised: a) reluctance to the partner $(\mathrm{OR} * 2.25,95 \% \mathrm{Cl}$ : $1.15-$ $4.39), b)$ getting married out of fear of being alone (OR **2.69, 95\% Cl: 1.42-5.11), c) passive-aggressive behaviour in conflicts with the partner (OR * $1.55,95 \%$ $\mathrm{Cl}: 1.09-2.20)$, and d) unsatisfactory sex life (OR *1.69, 95\% Cl: 1.09-2.62).

\section{The co-occurrence of vomiting and} stressful situations in males and females

Females who vomited in stressful situations reported significantly more often two sorts of reasons for building a sexual relationship. These were: family or friends pressure $(\mathrm{OR} * 2.38,95 \% \mathrm{Cl}: 1.25-4.54)$ and the desire to become independent (OR *1.63, 95\% Cl: $1.12-$ 2.37). Moreover, they also reported: feeling indifferent to the partner $(\mathrm{OR} * 1.52,95 \% \mathrm{Cl}: 1.12-2.06)$, considering the relationship to be unreliable because of "external circumstances" (OR * $1.51,95 \% \mathrm{Cl}: 1.11-2.05)$, calling the police during marital quarrels $\left(\mathrm{OR}{ }^{* *} 1.88,95 \% \mathrm{Cl}: 1.32-\right.$ 2.69), long interpersonal relationships interspersed with short and transient sexual contacts (OR * $1.75,95 \% \mathrm{Cl}$ : 1.02-2.98), short (few months or even few weeks) duration of the current relationship at the time of admission to the day hospital (OR ${ }^{* *} 1.70,95 \% \mathrm{Cl}$ : 1.18-2.44), and early marriage - before the age of 19 years (OR* $1.57,95 \% \mathrm{Cl}: 1.08-2.30)$. Vomiting in case of distress in females was associated with a greater variety of stressful situations than in males. In males, vomiting when nervous co-occurred significantly more often with: asymmetric efforts to establish relationship - more effort put by man (OR * $1.59,95 \% \mathrm{Cl}: 1.05-2.41)$, hatred towards the partner (OR *4.16, 95\% Cl: 1.11-15.62), ongoing breakdown of the relationship (OR **2.03, 95\% Cl: 1.32-3.14), feeling worse than the partner (OR $\left.{ }^{\star} 1.73,95 \% \mathrm{Cl}: 1.17-2.56\right)$, calling the police during marital quarrels ( $\mathrm{OR} * 2.78,95 \% \mathrm{Cl}: 1.27-6.06)$, meddling in the relationship committed by a third party (OR *3.67, 95\% Cl: 1.38-9.76), rare episodes of sexual intercourse (OR **1.75, 95\% Cl: 1.19-2.58), conflicts with partner's father $\left(O R{ }^{* *} 1.91,95 \% \mathrm{Cl}: 1.22-3.00\right)$, and living with

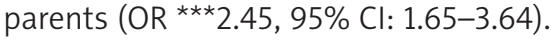

\section{The co-occurrence of appetite loss and stressful situations in males and females}

Loss of appetite in women coexisted significantly more often with: marriage under pressure or coercion (OR *2.34, 95\% Cl: 1.20-4.56), feeling worse than the partner (OR $\left.{ }^{* * *} 1.57,95 \% \mathrm{Cl}: 1.29-1.90\right)$, and feeling that the relationship has been very bad (OR * 1.54 , 95\% Cl: 1.13-2.11). Men reported significantly more often: relationship breakdown (OR *1.67, 95\% Cl: 1.14-2.44) 
and meddling in the relationship committed by a third party $(\mathrm{OR} * 3.68,95 \% \mathrm{Cl}: 1.19-11.35)$.

\section{The co-occurrence of nausea and stressful situations in males and females}

In females complaining of nausea, the first marriage was made significantly more often at the age of 1920 years (OR $\left.{ }^{\star} 1.51,95 \% \mathrm{Cl}: 1.18-1.93\right)$, and at the time of admission to the hospital it had lasted for several weeks or months $\left(\mathrm{OR}{ }^{*} 1.52,95 \% \mathrm{Cl}: 1.07-2.17\right)$. Males suffering from nausea reported significantly more often: calling the police during marital quarrels $(\mathrm{OR} * 2.22$, 95\% Cl: 1.05-4.70), passive-aggressive behaviour during conflicts with the partner (OR **1.62, 95\% Cl: 1.16-2.25), feeling worse than the partner $\left(\mathrm{OR}{ }^{*} 1.51,95 \% \mathrm{Cl}: 1.09-\right.$ 2.09 ), and conflicts with partner's father (OR ** 1.82 , $95 \% \mathrm{Cl}: 1.28-2.58)$.

\section{Coexistence of heartburn and stressful situations in males and females}

Women suffering from heart burn were significantly more likely to report a desire to become independent as a reason for marriage ( $\left.O{ }^{*}{ }^{\star} 1.62,95 \% \mathrm{Cl}: 1.13-2.31\right)$. They also reported more often long interpersonal relationships interspersed with short and transient sexual contacts (OR *1.99, 95\% Cl: 1.19-3.35). Men were significantly more likely to report: entering into marriage because they got used to the partner $\left(\mathrm{OR}{ }^{* *} 2.50,95 \% \mathrm{Cl}\right.$ : 1.32-4.72) and because of some commitments/feelings of obligation (OR * $1.67,95 \% \mathrm{Cl}$ : 1.00-2.81). They also believed that their partner put more effort into establishing the relationship than themselves (OR ***1.81, 95\% Cl: 1.31-2.49). Moreover, they often reported: police interventions during interpersonal conflicts (OR *2.52, 95\% Cl: 1.16-5.46), passive-aggressive silence (OR ${ }^{* *} 1.87,95 \% \mathrm{Cl}: 1.34-2.61$ ), and the sense that the relationship is uncertain because of the partner's travels or a love triangle (OR * $1.64,95 \% \mathrm{Cl}$ : 1.04-2.60). Males suffering from heartburn also often reported: parallel long-term and short-term sexual relationships (OR $\left.{ }^{*} 1.73,95 \% \mathrm{Cl}: 1.03-2.89\right)$ and periodic conflicts with the partner's father (OR $\left.{ }^{\star \star} 1.70,95 \% \mathrm{Cl}: 1.20-2.42\right)$.

\section{Coexistence of flatulence and stressful situations in males and females}

Females suffering from flatulence were significantly more likely to report passive-aggressive silence during conflicts with the partner (OR ${ }^{* * *} 1.54,95 \% \mathrm{Cl}$ : 1.22-1.94). Males with the same symptoms reported significantly more often: police interventions during interpersonal conflicts (OR $\left.{ }^{*} 2.17,95 \% \mathrm{Cl}: 1.01-4.63\right)$, feeling uncertain because of partner's journey, love triangle, etc. (OR *1,65, 95\% Cl: 1.04-2.61), and sexual preferences other than genital-heterosexual - such as homosexual, autosexual, etc. (OR *2.17, 95\% Cl: 1.02-4.63).

\section{Discussion}

The results of the study are evidently limited to a non representative population of patients admitted to a day hospital for neurotic and behavioural disorders. They relate to people who are generally healthy and relatively young, and whose symptoms can be considered as functional. These symptoms are important signs of neurotic disorders, especially somatoform or anxiety disorders. That is why it seems reasonable to analyse the psychological context in which the symptoms occur. Psychological context has been addressed by many authors with regard to irritable bowel syndrome and functional dyspepsia. In this study the focus was directed at examining the current situation of patients and current stressful events in their lives (data was gathered using a structured Life Inventory, which was filled out by patients when they were admitted to the hospital). Therefore, the situations and factors associated with the subject's adulthood, not childhood (as was done in other studies), were taken into account $[12,16]$.

The prevalence of functional gastrointestinal symptoms in patients admitted to day hospital for neurotic and behavioural disorders substantially exceeds the prevalence of such symptoms in the general population - it is true not only for isolated symptoms, for example constipation (estimated prevalence of constipation ranges from $3 \%$ to $20 \%$ [32]), but also for irritable bowel syndrome and functional dyspepsia [2]. Of course, the evaluation of complaints by the simplified symptom checklist is vague and subjective. The symptom checklist used in this study referred to symptoms that met two criteria: 1) they had been observed by the patient during 1 week before the examination, and 2) they were annoying for the person. That is why we can assume that some gastrointestinal symptoms were probably omitted in this study.

The results of the study confirm the widespread belief that functional gastrointestinal symptoms are associated with interpersonal stressors. These stressors include: cooperation difficulties or even conflicts with the patient's partner, asymmetric relationship, dysfunctional motivation to establish a relationship, "sexual mismatch", unbalanced distribution of power in the relationship, a sense of not being loved, etc. The observations are consistent with the descriptions of the distorted relationships in neurotic patients [33].

In conclusion, because of the association between functional gastrointestinal symptoms and stressful situations, it has been suggested (as van Tilburg et al. did 
before [34]) that psychological interventions or even psychotherapy be included in the process of treating non-psychiatric patients. It is also recommended that thediagnostic process be enriched with psychological diagnosis focused on the psychological context of somatic symptoms. This kind of enhanced diagnosis will undoubtedly facilitate the process of treatment [35].

\section{Conclusions}

Functional gastrointestinal symptoms are highly prevalent among patients admitted to the day hospital for neurotic and behavioural disorders (40-50\% of patients suffer from such symptoms). The most common complaints in women include: loss of appetite (52\%), nausea (49\%), and constipation and flatulence (45\%). In men, the most common complaints include: loss of appetite (47\%), heartburn (44\%), and flatulence (43\%). The analysed gastrointestinal symptoms are associated with the patient's current interpersonal difficulties, such as conflicts with the partner/spouse or the partner's parents. It has also been established that the majority of current interpersonal difficulties coexist with vomiting in stressful situations. The results suggest that in many cases symptoms of anxiety disorders (ICD-10 F40 and F41) or somatisation disorders (ICD-10 F45) may coexist with IBS and functional dyspepsia.

\section{Conflict of interest}

The authors declare no conflict of interest.

\section{References}

1. Jones MP, Crowell MD, Olden KW, et al. Functional gastrointestinal disorders: an update for the psychiatrist. Psychosomatics 2007; 48: 93-102.

2. Piotrowicz G, Stępień B, Rydzewska G. Socio-demographic characteristics of patients with diagnosed functional dyspepsia. Prz Gastroenterol 2013; 8: 354-65.

3. Lackner JM, Gudleski GD, Thakur ER, et al. The impact of physical complaints, social environment, and psychological functioning on IBS patients' health perceptions: looking beyond Gl symptom severity. Am J Gastroenterol 2014; 109: 224-33.

4. Sertbas Y, Belli H, Piskinpasa N, et al. Assessment of psychiatric symptoms and co-morbidities in patients with irritable bowel syndrome. West Indian Med J 2012; 61: 544-8.

5. Sinagra E, Romano C, Cottone M. Psychopharmacological treatment and psychological interventions in irritable bowel syndrome psychological interventions in irritable bowel syndrome. Gastroenterol Res Pract 2012; 2012: 486067. doi: 10.1155/2012/486067.

6. Lee SY, Park MC, Choi SC, et al. Stress, coping, and depression in non-ulcer dyspepsia patients. J Psychosom Res 2000; 49: 93-9.

7. Song EM, Jung HK, Jung JM. The association between reflux esophagitis and psychosocial stress. Dig Dis Sci 2013; 58: 471-7.
8. Walter SA, Jones MP, Talley NJ, et al. Abdominal pain is associated with anxiety and depression scores in a sample of the general adult population with no signs of organic gastrointestinal disease. Neurogastroenterol Motility 2013; 25: E741-76.

9. Sugaya N, Yoshida E, Yasuda S, et al. Irritable bowel syndrome, its cognition, anxiety sensitivity, and anticipatory anxiety in panic disorder patients. Psychiatry Clin Neurosci 2013; 67: 397-404.

10. Lackner JM, Gudleski GD, Blanchard EB. Beyond abuse: the association among parenting style, abdominal pain, and somatization in IBS patients. Behav Res Ther 2004; 42: 41-56.

11. Nicholl BI, Halder SL, Macfarlane GJ, et al. Psychosocial risk markers for new onset irritable bowel syndrome - results of a large prospective population-based study. Pain 2008; 137: 147-55.

12. Sobański JA, Klasa K, Rutkowski K, et al. Parental attitudes recollected by patients and neurotic disorders picture - sexuality-related and sexuality-unrelated symptoms [Polish]. Psychiatr Pol 2013; 47: 827-51.

13. Surdea-Blaga T, Baban A, Dumitrascu DL. Psychosocial determinants of irritable bowel syndrome. World J Gastroenterol 2012; 18: 616-26.

14. Phillips K, Wright BJ, Kent S. Psychosocial predictors of irritable bowel syndrome diagnosis and symptom severity. J Psychosom Res 2013; 75: 467-74.

15. Locke GR 3rd, Weaver AL, Melton LJ 3rd, et al. Psychosocial factors are linked to functional gastrointestinal disorders: a population based nested case-control study. Am J Gastroenterol 2004; 99: 350-7.

16. Sobański JA, Klasa K, Müldner-Nieckowski Ł, et al. Childhood sexual traumatic events and sexual life and relationship of a patient [Polish]. Psychiatr Pol 2013; 47: 411-31.

17. Sonneveld LP, Brilleslijper-Kater SN, Benninga MA, et al. Prevalence of child sexual abuse in pediatric patients with chronic abdominal pain. J Pediatr Gastroenterol Nutr 2013; 56: 475-80.

18. Hillilä MT, Siivola MT, Färkkilä MA. Comorbidity and use of health-care services among irritable bowel syndrome sufferers. Scand J Gastroenterol 2007; 42: 799-806.

19. Spiegel BM, Kanwal F, Naliboff B, et al. The impact of somatization on the use of gastrointestinal health-care resources in patients with irritable bowel syndrome. Am J Gastroenterol 2005; 100: 2262-73.

20. North CS, Downs D, Clouse RE, et al. The presentation of irritable bowel syndrome in the context of somatization disorder. Clin Gastroenterol Hepatol 2004; 2: 787-95.

21. North CS, Hong BA, Alpers DH. Relationship of functional gastrointestinal disorders and psychiatric disorders: implications for treatment. World J Gastroenterol 2007; 13: 2020-7.

22. Walker EA, Gelfand MD, Gelfand AN, et al. The relationship of current psychiatric disorder to functional disability and distress in patients with inflammatory bowel disease. Gen Hosp Psychiatry 1996; 18: 220-9.

23. Noyes R Jr, Cook B, Garvey M, Summers R. Reduction of gastrointestinal symptoms following treatment for panic disorder. Psychosomatics 1990; 31: 75-9.

24. Duddu V, Isaac MK, Chaturvedi SK. Somatization, somatosensory amplification, attribution styles and illness behaviour: a review. Int Rev Psychiatry 2006; 18: 25-33. 
25. Sobański JA. Contemporary research directions in "Polish Psychiatry" [Psychiatria Polska] on the basis of publications in the years 2010-2012. A preliminary report [Polish]. Psychiatr Pol 2012; 46: 691-707.

26. Janas-Kozik M, Zejda J, Stochel $M$, et al. Orthorexia - a new diagnosis? [Polish]. Psychiatr Pol 2012; 46: 441-50.

27. Błachno M, Bryńska A. Comorbidity and characteristic of obsessive-compulsive symptoms in anorexia nervosa [Polish]. Psychiatr Pol 2012; 46: 1019-28.

28. Dudek D, Sobański JA. Mental disorders in somatic diseases. Psychopathology and treatment. Pol Arch Med Wewn 2012; 122: 624-9.

29. Pawełczyk T, Pawełczyk A, Rabe-Jabłońska J. Before you diagnose a patient with a conversion disorder, perform a thorough general medical and neurological examination. Case study [Polish]. Psychiatr Pol 2012; 46: 483-92.

30. Rome III Diagnostic Criteria for FGIDs. Appendix A. website: www.romecriteria.org/assets/pdf/19_Romell__apA_885-898. pdf [accessed 10.09.2014].

31. Krawczyńska A, Maciejewska K, Pawlik M, et al. Selected aspects of diagnosis and treatment of irritable bowel syndrome in clinical practice of family doctors and internal medicine specialists [Polish]. Prz Gastroenterol 2012; 7: 367-73.

32. Choung RS, Locke RGIII, Rey E, et al. Factors associated with persistant and non-persistant chronic constipation, over 20 years. Clin Gastroenterol Hepatol 2012; 10: 494-500.

33. Małus A, Konarzewska B, Szulc A, et al. Functioning of the marriages applying for marital therapy [Polish]. Psychiatr Pol 2013; 47: 173-84.

34. van Tilburg MAL, Palsson OS, Whitehead WE. Which psychological factors exacerbate irritable bowel syndrome? Development of a comprehensive model. J Psychosom Res 2013. 74: 486-92.

35. Froch B, Zwolinska-Wcislo M, Betkowska-Korpala B, et al. The dynamics of emotional reactions in patients with inflammatory bowel disease. Prz Gastroenterol 2009; 4: 141-6.

Received: 21.11.2014

Accepted: 8.01.2015 